\title{
¿ES RESTAURATIVA la Ley Penal Juvenil?*
}

\author{
Por: Diana Britto Ruiz**
}

\section{Resumen}

De una manera novedosa la nueva Ley de Infancia y Juventud, ha incluido los mecanismos de justicia restaurativa para el tratamiento de jóvenes delincuentes. Pese a ser un importante avance en materia jurídica, esta Ley, al igual que el Código de Procedimiento Penal, propone aplicar la justicia restaurativa como un mecanismo desligado de procesos sociales, lo cual le resta su potencial educativo y preventivo. Este artículo hace un análisis de los elementos restaurativos que tiene la Ley a la luz de experiencias de justicia restaurativa juvenil en otros países y propone algunas pautas para acercar lo propuesto por la ley a una perspectiva restaurativa más amplia.

\section{Palabras Claves}

Gestión de conocimiento, Capital social, Producción Cooperación, Redes Sociales, Trabajo Inmaterial

\section{IS JUVENILE PENAL LAW MODIFIABLE?}

\section{**Perfil}

Diana Britto Ruiz es Master en Estudios políticos de la Pontificia Universidad Javeriana de Cali, Psicóloga de la Universidad del Valle y actualmente adelanta un doctorado en Paz, Conflicto y Democracia en la Universidad de Granada en España. Es integrante del grupo de investigación DEIS (Democracia, Estado e Integración) de la Pontificia Universidad Javeriana de Cali. Sus temas de investigación son Justicia Restaurativa y Género sobre los que tiene varias publicaciones.

\section{Abstract}

In an innovative way, the new law "Infancia y Juventud" has included the legal mechanisms for the treatment of juvenile criminals. Although this is an important legal achievement, this law, as the same as the "Código the Procedimiento Penal", proposed to apply restorative justice as a separate mechanism of social processes which minimizes its educational and preventive potential. This paper analyses the restorative elements that the law has from its experience in juvenile restorative justice in other countries and proposes some guidelines to relate what the Law proposes to a wider perspective.

\section{Key Words}

Juvenile crime, restorative justice, Restoration, Juvenile criminals

Artículo: Recibido, 28 de septiembre de 2007; aprobado, 28 de noviembre de 2007

\footnotetext{
*Ponencia presentada en VI Congreso lberoamericano de Psicología Jurídica. Pontificia Universidad Javeriana, Bogotá. Noviembre de 2006.
} 
uando se lee en el proyecto de la Ley 139 sobre la "Finalidad del sistema de responsabilidad penal para adolescentes. En materia de responsabilidad penal para adolescentes tanto el proceso como las medidas que se tomen son de carácter pedagógico, específico y diferenciado respecto del sistema de adultos, conforme a la protección integral. El proceso deberá garantizar la justicia restaurativa, la verdad y la reparación del daño"1. Uno no puede menos que alegrarse por este importante avance en materia jurídica.

Hablar de una ley penal juvenil con perspectiva restaurativa es ponerse a la altura de países como Gran Bretaña, Australia, Canadá, Bélgica, Nueva Zelanda, Sudáfrica, por citar solamente algunos de los que han adoptado el modelo de justicia restaurativa en el tratamiento de la delincuencia juvenil. Pero żqué implica que se defina como restaurativa?

Si nos apegamos a lo que estos países vanguardistas en la materia hacen, deberíamos estar de cara a una ley que:

1. Entiende que el delito es un fenómeno que acontece entre personas y que por ello debe ser tratado en su dimensión social y no como una trasgresión de las normas.

2. Busca la reparación de las víctimas, y a través de ella la recuperación para la sociedad del victimario, es decir, no renuncia a su tarea educativa para con los jóvenes.

3. Entiende que los delincuentes pertenecen a una familia y comunidad y por lo tanto es con la participación activa de éstas que se puede plantear el proceso restaurativo, estableciendo niveles de responsabilidades.

4. Respeta el sistema judicial que le da marco y mantiene una estrecha relación con él.

5. El énfasis en el tratamiento del delito no está en la seguridad, sino en la construcción de valores y de una ética de la responsabilidad. Pues reconoce que el victimario ha dañado a la víctima, a la sociedad y a sí mismo.

6. Busca equilibrar el la relación de poder entre víctimas y victimarios.

7. A diferencia del modelo punitivo, la justicia restaurativa no se declara neutral, por el contrario, tiene una orientación moralizante.

\section{¿Qué es la Justicia Restaurativa?}

La justicia restaurativa representa un cambio en el paradigma de justicia que hasta hoy conocemos, pues busca introducir una nueva mirada a la justicia. Cambia el eje para la dinámica del proceso, que hasta este momento está representado por el protagonismo del delincuente o infractor, la justicia restaurativa da un lugar protagónico a la víctima y busca, desde su perspectiva, la transformación del delito y las condiciones que lo propiciaron, pero ello no se logra sin la colaboración del victimario, quien debe salir también beneficiado del proceso.

Esta forma de justicia supera la puramente reparativa en cuanto que no se limita a sanar el daño causado a la víctima, sino que procura además que el victimario, a través del reconocimiento de su culpa y de la realización de actuaciones para la reparación de la víctima y de sus relaciones con la sociedad. La Justicia Restaurativa es un modelo de justicia que aplicado con rigurosidad en cuanto a sus principios llevaría a indagar sobre las bases mismas de la violencia, los conflictos y/o delitos, los cuales según importantes teóricos de la paz como Johan Galtung (1969), tienen diferentes niveles de expresión que es necesario atender para una verdadera resolución, estos son la violencia física (manifestación evidente, por ejemplo el golpe, la lesión) la violencia estructural (aspectos que están en las bases mismas de la sociedad y que de alguna manera

1. Código de la Infancia y la Adolescencia. Texto Definitivo aprobado en Agosto 29 de 2006. Gaceta del Senado. AñoXV N³76. Septiembre 18 de 2006. Pág. 20. 
contribuyen a la manifestación física, son las expresiones de la marginalidad) y la violencia cultural (que es el relato que justifica el ejercicio de la fuerza o el lugar de subordinación de unas personas sobre otras).

Se trata de un modelo alternativo que busca obtener y mantener una paz justa para la sociedad con base en la verdad a través del diálogo, y que debe, en primer lugar, acercar a las víctimas y a la comunidad, dando a las primeras, la posibilidad de trascender su lugar de víctimas para que recuperen su dignidad, de ejercer sus derechos y de hacerlas capaces de transformar las situaciones de inequidad que las han puesto en el lugar de víctima. En segundo lugar, acercar al ofensor con la sociedad a través del reconocimiento de sus responsabilidades y de la realización de actos de reparación que le permitan re-situarse como persona y como ciudadano(a). Y en tercer lugar, debe acercar a las víctimas con sus victimarios, ya fortalecidas las primeras y comprometidos los segundos, con el acompañamiento de la comunidad que sirve como referente y garante en la transformación de la violencia.

En este sentido, la Justicia Restaurativa es una justicia, que si bien busca el concurso de los expertos y expertas en el tema jurídico, pone su mayor interés en comprender y transformar las bases que subyacen al delito y la violencia apelando a la creación de un pacto social y de una ética de la convivencia, atiende las personas inmersas en el conflicto, pues reconoce que los conflictos y delitos son entre personas y no la fría interpretación o trasgresión de un código o norma, y sobretodo reconoce que en cada conflicto, delito, y manifestación de violencia hay una historia, y una serie de elementos del orden estructural y cultural que lo complejizan.

En síntesis, podríamos decir que la Justicia Restaurativa es un modelo de justicia comunitaria que pone todo su énfasis en la dimensión social de los delitos y conflictos. Busca restaurar el lazo social dañado, a través de un proceso de reparación y reconciliación entre la víctima y el ofensor, con la mediación de la comunidad. No busca el encierro del infractor sino su rehabilitación a través de la reparación del daño. En un sentido radical, la Justicia Restaurativa procura modificar las relaciones desiguales e injustas que han dado origen a los conflictos y delitos.

\section{Algunas pautas del modelo de justicia restaurativa juvenil en el mundo:}

En varios de los países donde ha sido implementado un modelo de justicia restaurativa juvenil (Nueva Zelanda, Australia, Canadá, por ejemplo) se ha hecho tomando en consideración la pluralidad étnica y apelando a costumbres y tradiciones de los pueblos indígenas nativos. La cuestión es que las tradiciones de estos pueblos apelaban al sentido comunitario y a las costumbres que permitían darle un tratamiento alternativo a los casos con un enfoque que revalúa lo punitivo y permite manejar la situación llevando al delincuente a tomar conciencia y responsabilidad del daño causado, e implicando directamente a las familias en la resolución de cada caso.

Estas experiencias se basan en lo que se ha denominado la "vergüenza reintegrativa" que propone que la vergüenza es necesaria para mantener la salud de las relaciones sociales. La vergüenza no entendida como ataques y agresiones, ni como el escarnio público, sino como la vergüenza de reconocer la falta ante los ojos de los familiares, amigos y personas significativas por los que siente respeto $y$ admiración.

En estos países se usa predominantemente el mecanismo de los Grupos Familiares, en los que el caso es tratado por víctima y victimario con el acompañamiento de sus respectivas familias y de personas significativas de su entorno, con la facilitación de equipos conformados por especialistas y personas de la comunidad entrenadas para el manejo de estas situaciones. Son procesos largos, pues la preparación previa de víctima y victimario es fundamental para que se pueda llegar a un acuerdo restaurativo, es necesario que el encuentro se dé cuando la rabia y el deseo de venganza hayan sido elaboradas.

Este tipo de planteamientos hacen surgir cuestionamientos en torno a la aplicabilidad de este modelo en países o sociedades en las que no existe una cultura de lo comunitario, sin 
embargo, existe en Gran Bretaña, país en el que el modelo restaurativo para la delincuencia juvenil data de los años 80 del siglo XX y en su versión actual se denomina la Ley de "No Más Excusas" que propone 3 R's:

$\checkmark$ RESTAURACIÓN: los jóvenes ofensores piden perdón y hacen la reparación del daño a las víctimas.

$\checkmark$ REINTEGRACIÓN: los jóvenes delincuentes pagan a la sociedad y tratan de recomponer las relaciones con ella.

$\checkmark$ RESPONSABILIDAD; los jóvenes ofensores y sus familias asumen las consecuencias de sus conductas, aceptan responsabilidades y toman medidas para evitar futuros daños y delitos.

Para el funcionamiento del modelo el Estado ha dispuesto de gran cantidad de recursos para la preparación de los equipos que apoyan el proceso, tanto personas de la comunidad, como juristas y expertos de otras áreas, que pueden dar soporte al proceso. Así mismo, ha sido necesario un ejercicio de sensibilización a todas las autoridades que de una $u$ otra manera tienen participación en el proceso, oficiales de policía, jueces, funcionarios del sistema judicial.

Lo cierto es que hay tantos modelos de justicia restaurativa como países en el mundo donde se aplica, pero el denominador común en todos ellos es que se mantienen fieles a los principios de la justicia restaurativa y propician la participación de los tres actores (victimas, victimarios y comunidad) en el proceso.

\section{Lo restaurativo en la Ley Penal Juvenil Colombiana}

Hechas estas claridades podríamos pasar a revisar con más detenimiento lo que plantea la ley y examinar los verdaderos alcances restaurativos que propone.

Lo primero que puedo anotar sobre la ley, es que no reconoce, como tampoco lo hace la Ley Penal, el importante rol que juega en la justicia restaurativa la comunidad. En el modelo de Justicia Restaurativa que se aplica en otros contextos los actores y el proceso se representan como aparece en el Gráfico 1. Están en una estrecha relación que busca la reparación del daño a la víctima y la restauración del tejido social, así pues, se le permite a integrantes de la comunidad participar activamente en el proceso. La justicia restaurativa es una justicia que puede ser aplicada por legos, no exige la presencia de expertos juristas.

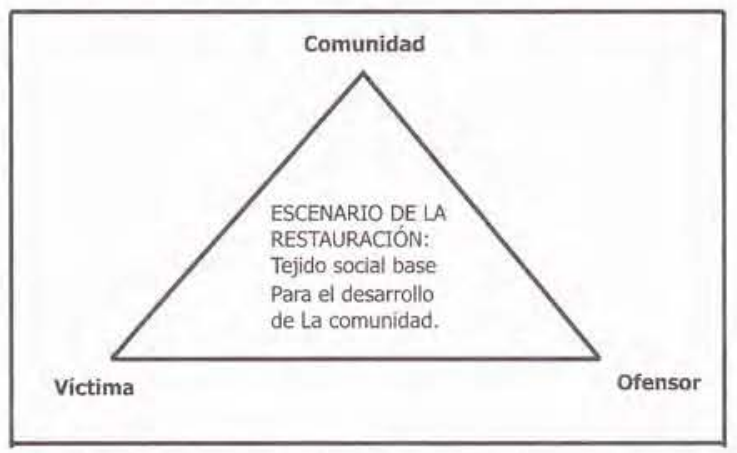

Gráfico 1: Componentes de la Justicia Restaurativa (McCold y Wachetel, 2003).

En segundo lugar al leer la ley queda la sensación de que lo restaurativo como tal está fuertemente mutilado por una comprensión limitada de sus principios y alcances, como resultado tenemos una ley que enuncia lo restaurativo pero sigue moviéndose dentro del esquema de lo punitivo. Esto puede apreciarse en el hecho de que la mayoría del articulado está dirigido a garantizar el debido proceso (cosa por demás muy importante) pero limitando lo restaurativo a pequeños espacios dentro de la lógica del castigo.

La justicia restaurativa exige un primer arreglo de voluntades, pero se consolidará, solamente, cuando se activen procesos de restauración que den respuesta al fenómeno del delito en toda su magnitud, es decir, atendiendo a su historia y a las bases culturales y estructurales que subyacen a él. Sin embargo, la Ley, en el artículo 176 asimila sanción a restauración, dejando de lado la posibilidad de que pueda plantearse la restauración, en el marco de un proceso que no necesariamente implique sanción.

Artículo. 176. Finalidad de las sanciones. Las sanciones señaladas en el artículo anterior tienen una finalidad protectora, educativa $y$ restaurativa, y se aplicarán con el apoyo de la 
familia y de especialistos... El juez podrá modificar en función de las circunstancias individuales del adolescente y sus necesidades especiales las medidas impuestas.

En la ley Penal Juvenil lo restaurativo no es desarrollado plenamente y por ello es posible pensar en que se valdrá de los desarrollos presentados en el Código de Procedimiento Penal en términos de mecanismos: La Conciliación Preprocesal, la Mediación y la Conciliación en el Incidente de Reparación Integral. Esto me preocupa especialmente, pues pese a que la conciliación y la mediación son importantes herramientas para la resolución de disputas, no son por si mismas restaurativas si no son usadas con apego a la filosofía y los principios restaurativos.

Otro aspecto a resaltar en el artículo 169 es el de la inclusión de los padres como garantes del compromiso con la restauración, un avance importante en materia de ley penal juvenil, pues compromete a la familia con el hecho y su resolución. Sin embargo, en el mismo artículo se propone que la reparación puede ser solicitada por la víctima, por el condenado o su defensor, pero esto desvirtúa el principio de la justicia restaurativa que señala que la única persona capaz de definir la restauración, de manera que dé por finalizada la situación de injusticia, es la víctima. El que la reparación sea solicitada o definida por otra persona desvirtúa el proceso restaurativo:

Artículo 169. Incidente de reparación. Los padres, - representantes legales, son solidariamente responsables, y en tal calidad, deberán ser citados o acudir al incidente de reparación a solicitud de la víctima del condenado o su defensor. Esta citación deberá realizarse en la audiencia que abra el trámite del incidente.

Y en el artículo 173 se plantea la reconciliación como un objetivo de la conciliación, pero no se define en términos de qué. Esto es discutible en tanto no se tenga claro que se entiende por reconciliación, pues existe la tendencia a considerarla perdón y esto es un ejercicio de la esfera individual que no puede ser lograda en la un ejercicio jurídico. De otra parte, si se considera una cuestión política, como la reconstitución de derechos, no es un aspecto que se pueda lograr en el ejercicio de conciliación solamente, implica un proceso:

Artículo 173. Del principio de oportunidad, la conciliación y la reparación integral de los daños. Las autoridades judiciales deberán facilitar en todo momento el logro de acuerdos que permitan la conciliación y la reparación de los daños, y tendrán como principio rector la aplicación preferente del principio de oportunidad. Estas se realizarán con el consentimiento de ambas partes y se llevarán a cabo con una visión pedagógica y formativa mediante la cual el niño, la niña o el adolescente pueda tomar conciencia de las consecuencias de su actuación delictiva y de las responsabilidades que de ella se derivan. Así mismo, el conciliador buscará la reconciliación con la víctima.

La verdadera restauración y hasta la reconciliación, radica en el hecho de que se logre transformar la dinámica desigual de poder entre victima y victimario, a partir de que la primera reciba una reparación material y simbólica adecuada que le permita trascender su lugar de sumisión, impotencia e indignidad; y el segundo, asuma la responsabilidad por sus actos ante la víctima y la sociedad recibiendo una sanción material y simbólica y comprometiéndose con la realización de la reparación de la víctima y la sociedad.

Así, pese a que la Ley Penal Juvenil se declara restaurativa sigue dando el papel protagónico a las autoridades judiciales cercenando la opción de que la justicia restaurativa abra la posibilidad a la comunidad y a equipos interdisciplinarios a manejen procesos que permitan el despliegue de su sabiduría y cumplan el rol de facilitadotes/as y veedores/as, dos elementos claves en su sentido de transformación y construcción de una ética de la convivencia.

\section{Pautas para pensar un modelo de Justicia Restaurativa Juvenil en Colombia}

1. Es perfectamente posible la aplicación de justicia restaurativa juvenil, pero no se trata de insertarla dentro del mismo esquema punitivo, sino de abrirle un marco de actuación que permita el despliegue de sus posibilidades. 
2. En el sistema judicial colombiano ha imperado una lógica de la eficiencia y la celeridad que busca descongestionarlo y dar fácil trámite a los casos, sin embargo, y de cara a la responsabilidad que tenemos en relación con los jóvenes delincuentes, la perspectiva restaurativa debe mantenerse fiel a sus principios y llevar su propia lógica en el manejo de los casos, aunque sean lentos.

3. Aplicar un modelo de justicia restaurativa implica por lo menos dos cuestiones, una fuerte inversión de recursos financieros para preparar las condiciones y mantener los equipos de trabajo en las zonas, y una campaña educativa y de sensibilización que generen las condiciones y la sostenibilidad de esta otra perspectiva de la justicia.

4. No se debe reducir lo restaurativo a simples mecanismos, pues pierde su sentido y razón de ser. Lo restaurativo está directamente ligado a la transformación de la injusticia y para ello es necesario atender las causas estructurales y culturales latentes en él. Y esto se logra trascendiendo la perspectiva de corto plazo de resolución del caso y dar paso a procesos de largo plazo que brinden atención integral a víctimas y victimarios.

5. Pese a todas las preguntas y dudas que esta ley ofrezca, es necesario resaltar que con ella hemos avanzado en términos de justicia pues da cabida a otros esquemas de justicia en perfecta sintonía con la pluralidad jurídica que propone la Constitución Política.

6. La justicia restaurativa es una oportunidad para transformar la relación que las personas tienen con la justicia y por ello debe tener cabida y significación en el discurso académico a todos los niveles, desde la formación básica, hasta los currículos de los programas de derecho y ciencias sociales, pues su perspectiva filosófica y moralizante abren la posibilidad de la construcción de una ética del respeto y la convivencia que permitan fortalecer el modelo democrático.

\section{BIBLIOGRAFÍA}

BERISTAIN, A. S.J (1998). Criminología y Victimología La alternativa re-creadoras al delito". Colombia: Editorial Leyer Ltda.

BRITTO, R. Diana. Justicia Restaurativa Como Emancipación de Género. Ponencia presentada en el Simposio Internacional Justicia Restaurativa y Paz en Colombia. Universidad Javeriana Cali. Colombia, 2005. (en proceso de publicación)

BRITTO, D Y ORDÓÑEZ, J. Justicia Restaurativa Una Forma de Integración y Transformación Social. Ponencia presentada en el evento Reconciliación y Derechos Humanos: la noviolencia y la resistencia civil como instrumentos para la reconciliación en Bogotá, Diciembre de 2004.

BRITTO, D Y ORDÓÑEZ, J. (2003). Justicia Restaurativa: "Uno mata por amor a la vida". Colombia. Informe de Investigación. En proceso de publicación.

CARRILLO, A. (2000). Modernidad y Nuevos Sentidos de lo Comunitario. En Educación Hoy, 29 (141). 33-48

CARRILLO, A. (2002). Vínculos comunitarios y reconstrucción social. Revista Colombiana de Educación, (3). 43-66

CÓDIGO DE LA INFANCIA Y LA ADOLESCENCIA. Código de la Infancia y la Adolescencia. Texto Definitivo aprobado en Agosto 29 de 2006. Gaceta del Senado. Año XV No376. Septiembre 18 de 2006.

CRAWFORD, Adam. NEWBURN, Tim. Youth Offending and Restorative Justice. Implementing reform in youth justice. Willan Publishing. UK. 2003.

DOUCET, IAN. (1998). Buscando la Paz del Mundo. Manual de recursos para la transformación del Conflicto. (comp.). Colombia: Clara.

ELIAS, Norbert. La Civilización de los Padres y Otros Ensayos. Ensayo teórico sobre las 
relaciones entre establecidos y marginados. Grupo Editorial Norma. Bogotá. 1998

FISAS, V. (1998). Cultura de Paz y gestión de Conflictos. España: UNESCO.

FITZDUFF, M. (1998). Más allá de la violencia. Procesos de resolución de Conflicto en Irlanda del Norte. España: Gernika Gogoratuz.

FRIDAY, Paul. C. Ediciones Centrales en Justicia Restitutiva. Documento que se presenta al Instituto Nacional de Ciencias Penales. Octubre 2000.

GALTUNG, J. (2003). Teoría del conflicto. En: Paz por medios pacíficos: paz y conflicto, desarrollo y civilización. España: Gernika Gogoratuz.

GALTUNG, Johan." Tras la Violencia, 3R: Reconstrucción, Reconciliación, Resolución. Afrontando los efectos visibles e invisibles de la guerra y la violencia". Colección Red Guernika. Bilbao, España. 1998.

GARCÍA, Mauricio. DE SOUSA SANTOS, Boaventura. (2001). Caleidoscopio de las Justicias en Colombia. Siglo del Hombre Editores. Colombia.

LEDERACH, J. P. (1995). ¿Conflicto y Violencia? iBusquemos Alternativas Creativas! Colombia: Clara

LEY 906 de 2004 o Nuevo Código de Procedimiento Penal. Colombia.

LÓPEZ, Mario. (2002). Noviolencia y cambio(s) social (es). actas del I Congreso Hispanoamericano de Educación y Cultura de Paz y Noviolencia. España: Universidad de Granada. Recuperado de la World Wide Web: http:// www.ugr.es/ - eirene/lopezmar.htm.

MARTÍN-BARÓ, Ignacio. Sistema, Grupo y Poder. Psicología Social desde Centroamérica. UCA. Salvador. 1898.

MCCOLD, P. y WACHTEL T. (2003). En Busca de un Paradigma: una teoría sobre Justicia Restaurativa. Ponencia presentada en el XIII Congreso Mundial sobre Criminología, del 10 al
15 de agosto de 2003, en Rîo de Janeiro. International Institute for Restorative Practicas. Disponible en http://iirp.org/library/paradigm_span.html MOCKUS, A Y CORZO, J. (2001).Divorcio entre ley, moral y cultura. Recuperado de la World Wide web: http://www.idct.gov.co/descargas/documentos word/cultura_ciu/doc_rel/Ley_Moral_Cultura.d oc. 